\title{
Intracranial hypertension and cerebral ischemia after severe traumatic brain injury
}

\author{
Roman Hlatky, M.D., Alex B. Valadka, M.D., and Claudia S. Robertson, M.D. \\ Department of Neurosurgery, Wayne State University, Detroit, Michigan; and Department of \\ Neurosurgery, Baylor College of Medicine, Houston, Texas
}

\begin{abstract}
Arterial hypotension and intracranial hypertension are detrimental to the injured brain. Although artificial elevation of cerebral perfusion pressure (CPP) has been advocated as a means to maintain an adequate cerebral blood flow $(\mathrm{CBF})$, the optimal CPP for the treatment of severe traumatic brain injury (TBI) remains unclear. In addition, $\mathrm{CBF}$ evolves significantly over time after TBI, and CBF may vary considerably in patient to patient. For these reasons, a more useful approach may be to consider the optimal CPP in an individual patient at any given time, rather than having an arbitrary goal applied uniformly to all patients. Important information for optimizing CBF is provided by monitoring intracranial pressure in combination with assessment of the adequacy of CBF by using global indicators (for example, jugular oximetry), supplemented when appropriate by local data, such as brain tissue oxygen tension.
\end{abstract} KEY WORDS • cerebral blood flow $\bullet$ cerebral ischemia $\bullet$ cerebral perfusion pressure $\bullet$
intracranial hypertension $\bullet$ intracranial pressure $\bullet$ traumatic brain injury

Intracranial hypertension and cerebral ischemia are the two most important secondary injury processes that can be anticipated, monitored, and treated in the intensive care unit. Prompt detection and treatment may eliminate potential secondary insults before they cause severe and irreversible injury to the brain.

\section{Posttraumatic Intracranial Hypertension: Scope of the Problem}

Intracranial hypertension is a common occurrence in patients in a severe TBI-induced coma. It is a widespread misconception that ICP will always be low after evacuation of a large intracranial hematoma. Intracranial hypertension has been reported in more than $50 \%$ of patients with severe TBI in whom an intracranial mass is evacuated. ${ }^{17}$ Postoperative intracranial hypertension may be caused by diffuse cerebral edema, progressive enlargement and swelling of focal contusions, postoperative hematomas at the operative site or at new sites, or various systemic complications. The incidence of intracranial hypertension is greater after evacuation of an intracerebral

\footnotetext{
Abbreviations used in this paper: $\mathrm{CBF}=$ cerebral blood flow; $\mathrm{CPP}=$ cerebral perfusion pressure $\mathrm{CT}=$ computerized tomography; $\mathrm{ICP}=$ intracranial pressure; $\mathrm{MCA}=$ middle cerebral artery; $\mathrm{rCBF}=$ regional $\mathrm{CBF} ; \mathrm{SjvO}_{2}=$ jugular venous oxygen saturation; $\mathrm{TBI}=$ traumatic brain injury.
}

hematoma than a subdural or epidural hematoma: $71 \mathrm{com}-$ pared with $39 \%$, respectively. ${ }^{17}$ The incidence of elevated ICP during hospitalization in patients without mass lesions has been reported to range from $30^{17}$ to as high as $80 \%^{2}$ in certain subpopulations.

The association between the severity of intracranial hypertension and poor outcome after severe head injury is well recognized. In one series, $77 \%$ of patients with an ICP below $15 \mathrm{~mm} \mathrm{Hg}$ experienced a favorable outcome, whereas only $43 \%$ of patients with an ICP above $15 \mathrm{~mm}$ $\mathrm{Hg}$ experienced a favorable outcome. ${ }^{14}$ Miller, et al., ${ }^{18}$ reported that the mortality rate increased from 18 to $92 \%$ and that the frequency of good outcomes decreased from 74 to $3 \%$ when cases of normal ICP were compared with those of intracranial hypertension in which the level could not be decreased to $20 \mathrm{~mm} \mathrm{Hg}$. Similarly, Saul and Duck$\mathrm{er}^{26}$ reported a $69 \%$ mortality rate in patients with an ICP greater than $25 \mathrm{~mm} \mathrm{Hg}$ compared with that of $15 \%$ in those in whom the ICP remained less than $25 \mathrm{~mm} \mathrm{Hg}$.

The relationship between elevated ICP and a poor outcome is not simply a reflection of the severity of the initial neurological injury. Severe intracranial hypertension can result in secondary cerebral injury by causing ischemia due to reduced CPP. Elevated ICP can also produce distortion and compression of the brainstem. Although no randomized clinical trial has been conducted to address this question, the authors of several clinical series have suggested that reduction of ICP to below 15 to $25 \mathrm{~mm} \mathrm{Hg}$ 
reduces the mortality rate after severe head injury. ${ }^{14,17,26}$ Most authorities currently recommend $20 \mathrm{~mm} \mathrm{Hg}$ as the threshold above which treatment should generally be initiated.

\section{Detection of Intracranial Hypertension}

Intracranial pressure cannot be reliably estimated by observing any clinical feature after severe TBI. Clinical symptoms of raised ICP, such as headache, nausea, and vomiting, are impossible to determine in comatose patients. Papilledema is uncommon after head injury, even in patients with intracranial hypertension. In one study, papilledema was seen in only $3.5 \%$ of 426 patients with severe TBI in whom the frequency of elevated ICP exceeded $50 \% .{ }^{28}$ Additionally, neurological signs that sometimes indicate the presence of elevated ICP, including pupillary dilation and decerebrate posturing, can occur in the absence of intracranial hypertension. Computerized tomography scanning-documented signs of brain swelling, such as midline shift and basal cistern compression, are consistent with raised ICP, but intracranial hypertension can occur in the absence of these findings. ${ }^{12}$

\section{Posttraumatic Cerebral Ischemia: Scope of the Problem}

The injured brain is exceptionally vulnerable to secondary ischemic insults, particularly hypotension and hypoxia, and the occurrence of secondary insults is associated with a poor neurological outcome after severe TBI. $^{4,21}$ Several factors may contribute to posttraumatic cerebral ischemia, including systemic arterial hypotension, increased ICP, cerebral edema, focal tissue compression from hematomas, and microvascular disease. . $8,13,19,22,27^{2}$

\section{Cerebral Blood Flow-Targeted Therapy}

Our group conducted a randomized clinical trial to evaluate a treatment strategy designed to maintain adequate $\mathrm{CBF}$ and to prevent secondary ischemic insults by maintaining a CPP of at least $70 \mathrm{~mm} \mathrm{Hg}$ and by avoiding treatments such as hyperventilation, which reduces CBF. ${ }^{24}$ This "CBF-targeted" treatment successfully reduced the incidence of jugular venous desaturation, the number of episodes of jugular venous desaturation, and the total duration of time that the $\mathrm{SjvO}_{2}$ was less than the critical threshold of $50 \%$. The observed reduction in jugular venous desaturations was associated with reductions in systemic hypotension and in hypocarbia. Even with adjustment for all demographic and injury severity-related variables that were significant, the risk of jugular venous desaturation remained 2.36-fold higher in the ICP-targeted treatment group. The CBF-targeted treatment strategy, however, increased the incidence of adult respiratory distress syndrome fivefold and failed to improve long-term neurological outcome. One interpretation of this study is that the beneficial effect of the CBF-targeted treatment was offset by systemic complications associated with maintaining blood pressure at an elevated level.

\section{Variability of Posttraumatic CBF Over Time}

Many investigators who have studied post-TBI CBF have emphasized various patterns of changes in CBF. In a few studies investigators have used serial measurements of CBF to examine closely the evolution of TBI over time..$^{15,23}$ Martin, et al..$^{15}$ described a phasic pattern of cerebral hemodynamic changes in 125 severely head-injured patients in whom the Glasgow Coma Scale score was lower than 9; the prospective study of these patients involved obtaining intravenous ${ }^{133} \mathrm{Xe}-\mathrm{CBF}$ measurements and cerebral metabolic and/or transcranial Doppler bloodflow velocities. An early hypoperfusion phase during the first 24 hours postinjury was characterized by a low CBF and normal MCA flow velocity. This was followed by a hyperemic phase between postinjury Days 1 and 3 during which $\mathrm{CBF}$ was normal or increased, with a rising MCA flow velocity and increasing hemispheric index. Later (postinjury Days 4-15), a period of vasospasm was demonstrated. This phase was associated with a low-normal CBF, high MCA flow velocity, and elevated hemispheric index. Bouma, et al., ${ }^{1}$ reported global or rCBF values less than or equal to $18 \mathrm{ml} / 100 \mathrm{~g} / \mathrm{min}$ in $31 \%$ of head-injured patients when the CBF evaluations were performed a mean of 3.1 hours postinjury, suggesting that most of the severe posttraumatic cerebral ischemia occurs very early after injury.

\section{Variability of Posttraumatic CBF by Region}

The same CBF patterns that have been described primarily with global CBF measurements can also occur regionally. In particular, hypoperfusion can occur in brain surrounding a focal contusion or underlying a subdural hematoma. Schroder, et al., ${ }^{27}$ observed mean rCBF values of $17.5 \mathrm{ml} / 100 \mathrm{~g} / \mathrm{min}$ in pericontusional brain. McLaughlin and Marion ${ }^{16}$ observed that CBF values within contused brain and in pericontusional brain were significantly lower than those in the surrounding brain. Focal hyperemia has been observed in $38 \%$ of patients, particularly in tissue adjacent to intraparenchymal or extracerebral focal lesions. ${ }^{25}$

\section{Detection of Cerebral Ischemia}

As with intracranial hypertension, no reliable clinical findings indicate the presence of cerebral ischemia. The neurological signs caused by brain injury usually obscure any focal findings that might be caused by secondary ischemia. Therefore, cerebral perfusion must be monitored to detect secondary cerebral ischemia after TBI.

The ideal monitoring technique for cerebral ischemia after TBI does not exist. This ideal monitor would give regional information about $\mathrm{CBF}$ because there can be marked posttraumatic regional differences in CBF. This ideal monitor would also provide continuous information because CBF evolves over time after injury. The available techniques fall under two general categories: those that monitor cerebral perfusion or blood flow and those that monitor CBF adequacy.

Techniques Based on Perfusion. The simplest measure of cerebral perfusion is the CPP. The CPP can be reduced by either decreases in blood pressure or increases in ICP. For equivalent levels of CPP, cerebral perfusion is impaired more by reductions in blood pressure than by increases in ICP. ${ }^{20}$ The CPP has at least two important physiological roles in the patient who has suffered a severe head injury. First, because CPP represents the pressure 
gradient acting across the cerebrovascular bed, it is an important factor in the regulation of CBF. Second, because CPP contributes to the hydrostatic pressure within the intracerebral vessels, it represents one of the factors that determine edema formation in the injured brain.

Techniques Based on Adequacy of Flow. Measures of cerebral oxygenation, such as $\mathrm{SjvO}_{2}$ or brain tissue $\mathrm{PO}_{2}$, have been used in place of quantitative CBF measurements because they indicate the adequacy of $\mathrm{CBF}$ relative to cerebral metabolic requirements. If the brain is hypoperfused, $\mathrm{O}_{2}$ extraction will be increased, and $\mathrm{SjvO}_{2}$ will be reduced. Intracranial hypertension was the most common cause of jugular venous desaturation reported in a prospective study of 116 patients with severe head injury, ${ }^{7}$ accounting for $44 \%$ of the total number of episodes. If $\mathrm{CBF}$ is appropriate for the brain's metabolic requirement, then $\mathrm{SjvO}_{2}$ will be normal. Often this information is more clinically useful than the absolute CBF values.

The major limitation of using $\mathrm{SjvO}_{2}$ as a monitor of $\mathrm{CBF}$ adequacy is that regional ischemia will not be identified. In conditions such as TBI, in which regional differences in CBF may occur, monitoring of brain tissue $\mathrm{PO}_{2}$ may have an important advantage. , $^{3,10,30}$ Normal values for brain tissue $\mathrm{PO}_{2}$ seem to be approximately 20 to 40 $\mathrm{mm} \mathrm{Hg}$, and the range of 8 to $10 \mathrm{~mm} \mathrm{Hg}$ may represent a critical threshold. Hoffman, et al., ${ }^{9}$ reported brain tissue $\mathrm{PO}_{2}$ in patients with single-positron emission CT-documented ischemia averaged $10 \pm 5 \mathrm{~mm} \mathrm{Hg}$ compared with $37 \pm 12 \mathrm{~mm} \mathrm{Hg}$ in the healthy brain. Valadka, et al., ${ }^{29}$ found that the likelihood of death following a severe head injury increased with increasing duration of time that brain tissue $\mathrm{PO}_{2}$ was below $15 \mathrm{~mm} \mathrm{Hg}$ and with any occurrence of a brain tissue $\mathrm{PO}_{2}$ less than $6 \mathrm{~mm} \mathrm{Hg}$. Kiening, et al., ${ }^{11}$ correlated serial measurements of both $\mathrm{SjvO}_{2}$ and brain tissue $\mathrm{PO}_{2}$ and found that an $\mathrm{SjvO}_{2}$ of $50 \%$ in general correlates with a brain tissue $\mathrm{PO}_{2}$ of $8.5 \mathrm{~mm} \mathrm{Hg}$.

\section{Recommended Monitoring Strategy}

It is clear from the descriptions of the available devices that none is ideal in the setting of TBI. No single monitor continuously provides high-resolution $\mathrm{rCBF}$ data. At present, a reasonable strategy is to obtain intermittent measurements of $\mathrm{rCBF}$, preferably by performing stable Xeenhanced CT scanning, to determine whether regional abnormalities of flow exist. If no hypoperfused regions are detected, then a global monitor, such as an $\mathrm{SjvO}_{2}$ catheter, should suffice. If significant regional heterogeneity of flow is detected, then brain tissue $\mathrm{PO}_{2}$ monitoring or a local CBF probe may be used as a local monitor near the hypoperfused area. This local monitor would be used in addition to a global monitor, such as an $\mathrm{SjvO}_{2}$ catheter (Fig. 1), which would still be needed because secondary ischemic insults are often global and usually transient. Finally, common systemic sources of secondary insults, such as blood pressure and oxygenation, should also be monitored.

\section{CONCLUSIONS}

Despite widespread recognition that systemic hypotension and intracranial hypertension are detrimental to the injured brain, the optimal CPP in patients with severe TBI

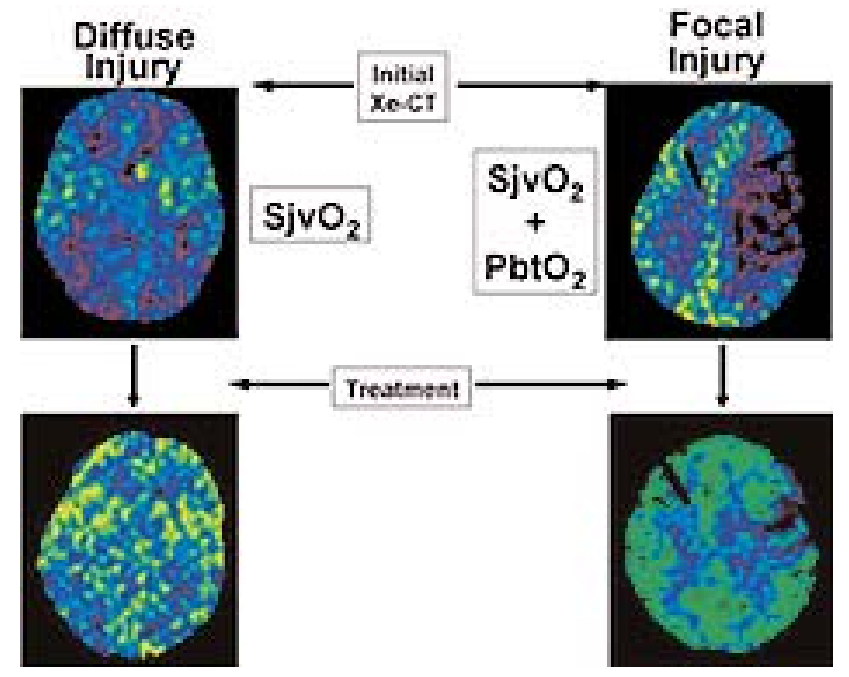

Fig. 1. Possible protocol for monitoring of the adequacy of $\mathrm{CBF}$ in patients who have suffered a severe TBI. At present, a reasonable strategy is to undertake intermittent measurements of $\mathrm{rCBF}$, preferably by the stable Xe-enhanced CT method, to determine whether regional flow abnormalities exist. If no hypoperfused regions are present, then global monitoring, such as $\mathrm{SjvO}_{2}$ assessment, should suffice. If significant regional abnormalities of flow are present, then global monitoring may be supplemented by regional monitoring of the affected area, such as with brain tissue $\mathrm{PO}_{2}\left(\mathrm{PbtO}_{2}\right)$ or local CBF probes.

and the relative importance of systemic blood pressure and ICP in contributing to optimal CPP remain debated. The normal pattern of CBF after brain injury is one of significant evolution over time. Furthermore, CBF may also vary markedly from patient to patient. For these reasons, consideration should be given to maintaining an optimal CPP in an individual patient at each specific moment in time, rather than having some arbitrary goal generalized in all patients. Monitoring of ICP together with continuous assessment of the adequacy of CBF by means of jugular venous oximetry and brain tissue $\mathrm{PO}_{2}$ monitoring are major components of CPP optimization.

\section{References}

1. Bouma GJ, Muizelaar JP, Stringer WA, et al: Ultra-early evaluation of regional cerebral blood flow in severely head-injured patients using xenon-enhanced computerized tomography. J Neurosurg 77:360-368, 1992

2. Bruce DA, Raphaely RC, Goldberg AI, et al: Pathophysiology, treatment and outcome following severe head injury in children. Childs Brain 5:174-191, 1979

3. Charbel FT, Hoffman WE, Misra M, et al: Cerebral interstitial tissue oxygen tension, $\mathrm{pH}, \mathrm{HCO}_{3}, \mathrm{CO}_{2}$. Surg Neurol 48: 414-417, 1997

4. Chesnut RM, Marshall LF, Klauber MR, et al: The role of secondary brain injury in determining outcome from severe head injury. J Trauma 34:216-222, 1993

5. Dings J, Meixensberger J, Roosen K: Brain tissue $\mathrm{pO}_{2}$-monitoring: catheter stability and complications. Neurol Res 19: 241-245, 1997

6. Gobiet W, Grote W, Bock WJ: The relation between intracranial pressure, mean arterial pressure and cerebral blood flow in patients with severe head injury. Acta Neurochir 32:13-24, 1975 
7. Gopinath SP, Robertson CS, Contant CF, et al: Jugular venous desaturation and outcome after head injury. J Neurol Neurosurg Psychiatry 57:717-723, 1994

8. Hekmatpanah J, Hekmatpanah CR: Microvascular alterations following cerebral contusion in rats. Light, scanning, and electron microscope study. J Neurosurg 62:888-897, 1985

9. Hoffman WE, Charbel FT, Edelman G: Brain tissue oxygen, carbon dioxide, and $\mathrm{pH}$ in neurosurgical patients at risk for ischemia. Anesth Analg 82:582-586, 1996

10. Kiening KL, Hartl $\mathrm{R}$, Unterberg $\mathrm{AW}$, et al: Brain tissue $\mathrm{pO}_{2}-$ monitoring in comatose patients: implications for therapy. Neurol Res 19:233-240, 1997

11. Kiening KL, Unterberg AW, Bardt TF, et al: Monitoring of cerebral oxygenation in patients with severe head injuries: brain tissue $\mathrm{PO}_{2}$ versus jugular vein oxygen saturation. J Neurosurg 85:751-757, 1996

12. Kishore PR, Lipper MH, Becker DP, et al: Significance of CT in head injury: correlation with intracranial pressure. AJR 137: 829-833, 1981

13. Marmarou A, Ward JD, Young HF, et al: Impact of ICP instability and hypotension on outcome in patients with severe head trauma. J Neurosurg (Suppl) 75:S59-S66, 1991

14. Marshall LF, Smith RW, Shapiro HM: The outcome with aggressive treatment in severe head injuries. Part I: the significance of intracranial pressure monitoring. J Neurosurg 50: 20-25, 1979

15. Martin NA, Patwardhan RV, Alexander MJ, et al: Characterization of cerebral hemodynamic phases following severe head trauma: hypoperfusion, hyperemia, and vasospasm. J Neurosurg 87:9-19, 1997

16. McLaughlin MR, Marion DW: Cerebral blood flow and vasoresponsivity within and around cerebral contusions. J Neurosurg 85:871-876, 1996

17. Miller JD, Becker DP, Ward JD, et al: Significance of intracranial hypertension in severe head injury. J Neurosurg 47: 503-516, 1977

18. Miller JD, Butterworth JF, Gudeman SK, et al: Further experience in the management of severe head injury. J Neurosurg 54:289-299, 1981

19. Miller JD, Dearden NM, Piper IR, et al: Control of intracranial pressure in patients with severe head injury. J Neurotrauma 9 (Suppl 1):S317-S326, 1992
R. Hlatky, A. B. Valadka, and C. S. Robertson

20. Miller JD, Stanek A, Langfitt TW: Concepts of cerebral perfusion pressure and vascular compression during intracranial hypertension. Prog Brain Res 35:411-432, 1972

21. Miller JD, Sweet RC, Narayan RK, et al: Early insults to the injured brain. JAMA 240:439-442, 1978

22. Pfenninger EG, Reith A, Breitig D, et al: Early changes of intracranial pressure, perfusion pressure, and blood flow after acute head injury. Part 1: An experimental study of the underlying pathophysiology. J Neurosurg 70:774-779, 1989

23. Robertson CS, Contant CF, Gokaslan ZL, et al: Cerebral blood flow, arteriovenous oxygen difference, and outcome in head injured patients. J Neurol Neurosurg Psychiatry 55:594-603, 1992

24. Robertson CS, Valadka AB, Hannay HJ, et al: Prevention of secondary ischemic insults after severe head injury. Crit Care Med 27:2086-2095, 1999

25. Sakas DE, Bullock MR, Patterson J, et al: Focal cerebral hyperemia after focal head injury in humans: a benign phenomena? J Neurosurg 83:277-284, 1995

26. Saul TG, Ducker TB: Effect of intracranial pressure monitoring and aggressive treatment on mortality in severe head injury. J Neurosurg 56:498-503, 1982

27. Schroder ML, Muizelaar JP, Bullock MR, et al: Focal ischemia due to traumatic contusions documented by stable xenon-CT and ultrastructural studies. J Neurosurg 82:966-971, 1995

28. Selhorst JB, Gudeman SK, Butterworth JF IV, et al: Papilledema after acute head injury. Neurosurgery 16:357-363, 1985

29. Valadka AB, Gopinath SP, Contant CF, et al: Relationship of brain tissue $\mathrm{PO}_{2}$ to outcome after severe head injury. Crit Care Med 26:1576-1581, 1998

30. Zauner A, Doppenberg E, Woodward JJ, et al: Multiparametric continuous monitoring of brain metabolism and substrate delivery in neurosurgical patients. Neurol Res 19:265-273, 1997

Manuscript received February 26, 2003.

Accepted in final form March 13, 2003.

Supported by National Institutes of Health grant PO1-NS38660

Address reprint requests to: Alex B. Valadka, M.D., Department of Neurosurgery, Baylor College of Medicine, 6560 Fannin, Suite 944, Houston, Texas 77030. email: avaladka@bcm.tmc.edu. 